Postgrad. MED. J. (1964), 40, 696

\title{
THE DIABETIC EYE
}

\author{
D. W. HILL, F.R.C.S. \\ Institute of Ophthalmology, London, W.C.1.
}

THE INTRODUCTION of insulin has transformed the management of diabetes mellitus bringing a greatly increased expectation of life with the result that a number of complications, some taking many years to develop, have become manitest. At the present time the impact of this revolution is being felt as a large population of patients with long established diabetes collects. Blindness due to diabetes has increased and diabetic retinopathy accounted for $11.3 \%$ of those under 60 years old registered blind in Great Britain in 1962 (Mooney, 1963). It seems appropriate in this article to deal at length with diabetic retinopathy and review the other ocular manifestations of diabetes briefly. For the sake of orientation the ocular changes in diabetes are listed in Table 1, while Table 2 indicates how various events may affect the eyes.

\section{RETINOPATHY}

\section{Clinical Manifestations}

Diabetic retinopathy is a disease of considerable variation both in severity, clinical appearance, and progress. It is seldom seen in the young diabetic of less than five years' duration (Collyer and Hazlett, 1961), but is often present at diagnosis in the maturity onset diabetic and may be the presenting lesion. The earliest clinical manifestations comprise a central punctate retinopathy (Ballantyne, 1947) with microaneurisms, dot hæmorrhages and small white spots grouped around the posterior pole of the eye. After a time larger hæmorrhages develop which have been likened to blots, round in shape with crenated poorly defined margins; set deeply in the retina in the inner molecular and nuclear layers, they contrast with the more superficial flame shaped hæmorrhages of hypertensive retinopathy which are moulded by the nerve fibre layer. Accompanying these hæmorrhages are small patches of waxy exudate. The retinopathy advances and spreads to involve larger areas of the retina but seldom affects the periphery of the fundus. Larger and more irregular hæmorrhages are seen which break through the layers of the retina to lie on its surface,
TABLE 1

OCULAR MANIFESTATIONS IN DIABETES $\stackrel{\frac{\Phi}{\varrho}}{\varrho}$

External Lid and conjunctival infections.

Anterior segment Pigmentary migration

Pupillary changes poor dilatation

Argyll Robertson pupil

Rubeosis iridis

hæmorrhagic glaucoma

Cataract

transient changes

diabetic (juvenile)

senile

Hypotension, in diabetic coma

Posterior segment Vitreous hæmorrhage

Retinopathy

Lipæmia retinalis

Optic neuritis

Subjective

phenomena

Transient changes in refraction

Weakness of accommodation 1

Aura of hypoglycæmia

\section{OCULAR MANIFESTATIONS ON CERTAIN OCCASIONS}

Presenting signs

Retinopathy and symptoms

Cataract

Transient refractive changes

Ophthalmoplegia

Optic neuritis

Diabetic coma

Ocular hypotension

Transient lens opacities

Lipæmia retinalis

Hypoglycæmia (early)

Subjective visual phenomena 
The extent to which venous changes occur in diabetic retinopathy varies considerably; a slight general dilatation is said to be the earliest sign of retinopathy but is difficult to detect. More definite are dilated segments, and these may be followed by the appearance of irregular beading of the veins, tortuosity and bizarre loops lying on the retina and projecting from its surface.

The term proliferative retinopathy implies the development of new vessels, a serious prognostic sign, for the majority of cases deteriorate and many become blind. Beetham (1963) found that five years elapsed on average between the onset and final stages of proliferative retinopathy. The stage at which proliferation commences varies from case to case, but there is always some venous abnormality present. New vessels grow in the plane of the retinal vessels and spread forwards into the vitreous to form delicate fronds, rete mirabile, commonly arising from the optic disc but also seen elsewhere taking origin from the retinal veins, Their walls are fragile so that bleeding frequently occurs into the retina and vitreous. At a later stage the fronds thicken with connective tissue to form retinitis proliferans, and in severe cases sheets of preretinal connective tissue form. Retinitis proliferans may also arise from the direct organisation of vitreous hæmorrhage (Ballantyne, 1947). Contraction of the retinitis proliferans and preretinal connective tissues leads to traction on the retina, shown by stress lines on the posterior vitreous face, and later retinal detachment.

Permanent loss of central vision in diabetic retinopathy is due to involvement of the macula by hæmorrhage, hard exudate or retinal detachment. Occasionally a frond of retinitis proliferans may spread in front of the macula obscuring vision. Complete blindness occurs from massive vitreous hæmorrhage, retinal detachment or intercurrent hæmorrhagic glaucoma.

It is difficult to summarise succinctly the natural history of diabetic retinopathy but three elements can be recognised, hæmorrhagic, venous and proliferative. Onset is usuallv marked by slight hæmorrhagic changes which progress and recruit hard exudates. venous changes run concurrently in varving degree. at a later stage proliferative changes may develop. An intricate clinical classification proposed bv Scott (1951) expresses this variabilitv. Larsen (1960b) makes a distinction between the retinonathv in middle-aged, older and iuvenile diabetics. The middle-aged diabetic, $20-40$ years old at the onset of diabetes, shows the evolu- tion just described, passing from a punctate retinopathy to increasing hæmorrhage and confluent exudates, and in a small proportion of cases to proliferative retinopathy. The older diabetic aged over 50 years at onset has a marked tendency to develop exudative changes at the macula with the formation of confluent plaques; later, glistening crystals form and the whole plaque gradually disperses to leave a scarred area; central vision fails as the plaque develops. Juvenile diabetics with onset of disease in the first 20 years of life show several differing patterns of retinopathy. It may develop along the lines of the middle-aged diabetic, or there may be an early onset of proliferative retinopathy initiated by vitreous detachment with preretinal and subhyaloid hæmorrhages; other cases progress very slowly but develop severe arteriosclerosis over a period of 20-30 years.

Hypertension frequently complicates diabetes, and the retinopathy of hypertension may complicate the appearance of diabetic retinopathy, but there is no doubt that diabetic retinopathy is a separate entity not dependent on hypertension for its existence (Duke Elder, 1940a). Soft exudates are seen from time to time in the course of diabetic retinopathy but are less conspicuous than those of hypertensive retinopathy.

Development of a fine stippled pigmentation of the macula (Jensen and Lundbaek, 1955) is occasionally encountered in iuvenile diabetics, the significance of the condition being that it is harmless and not associated with any loss of vision.

The differentiation of microaneurisms and punctate hæmorrhages can be difficult. If the lesion has a well defined spherical outline with a light reflex from the summit this is indicative of an aneurism, but such an appearance is not always seen. In other instances the duration of the lesion may help as hæmorrhages usually clear within a few weeks whilst aneurisms persist for long periods.

Fluorescence retinal photography (Dollery, Hodge and Engel, 1962) is a form of angiography in which the contrast medium, fluorescein, is injected intravencusly and photographed as it passes through the retina. Studies of diabetic retinopathy (Scott, Dollery, Hill, Hodge and Fraser, 1964) reveal many more microaneurisms and new vessels than seem evident clinically (Figs. 1 and 2). Aneurisms are usually grouped and in severe cases appear like bunches of grapes clustered - round a venule. After the passage of fluorescein some 


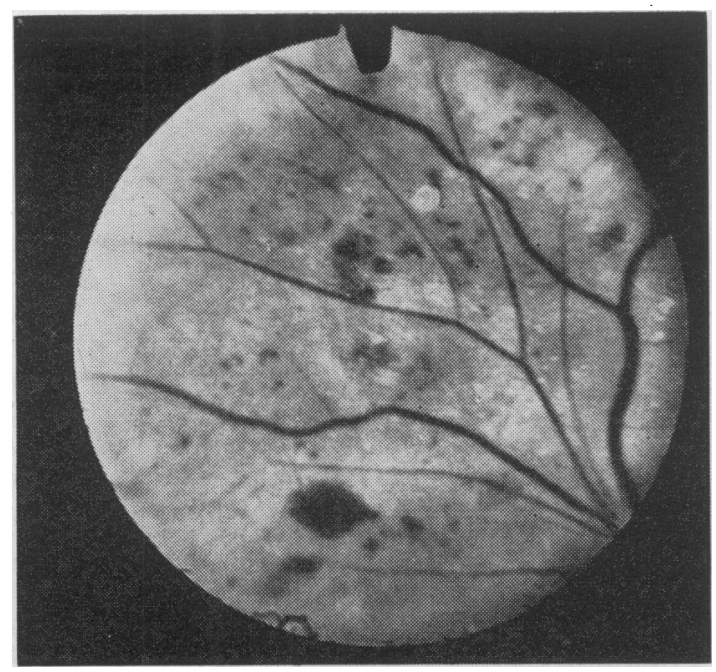

Fig. 1.-Reproduction of a colour transparency of the fundus oculi showing the right superior temporal field, from a patient with diabetic retinopathy. There are numerous hæmorrhages and some small exudates. This figure should be carefully compared with Figure 2.

aneurisms empty promptly, others more slowly, while others remain fluorescent for as long as ten minutes with leakage of the dye into the surrounding tissues. Similar leakage occurs from some new vessels, and to a marked extent from fronds of retinitis proliferans, whence dye passes into the vitreous. It is conjectured that this abnormal permeability may be associated with the haze in the vitreous found in active proliferative retinopathy.

\section{Incidence}

The incidence of diabetic retinopathy rises with the duration of diabetes. In a group of diabetics of all ages Larsen (1960a) found it to rise slowly during the first five years after the disease was diagnosed, then sharply; by ten years there was an equal incidence in nearly all age groups apart from patients under the age of 16 years in whom the complication was rare. Figures for the incidence of retinopathy vary widely depending in part on the criteria adopted for diagnosis; Larsen (1960a) notes an incidence reported in the literature of $30-80 \%$ after 15 years and $60-100 \%$ after 20 years.

It is difficult to ascertain how control of the diabetes is related to retinopathy. Keiding, Root and Marble (1952) found a reduced incidence in patients with good clinical control as compared to those with bad control, in groups

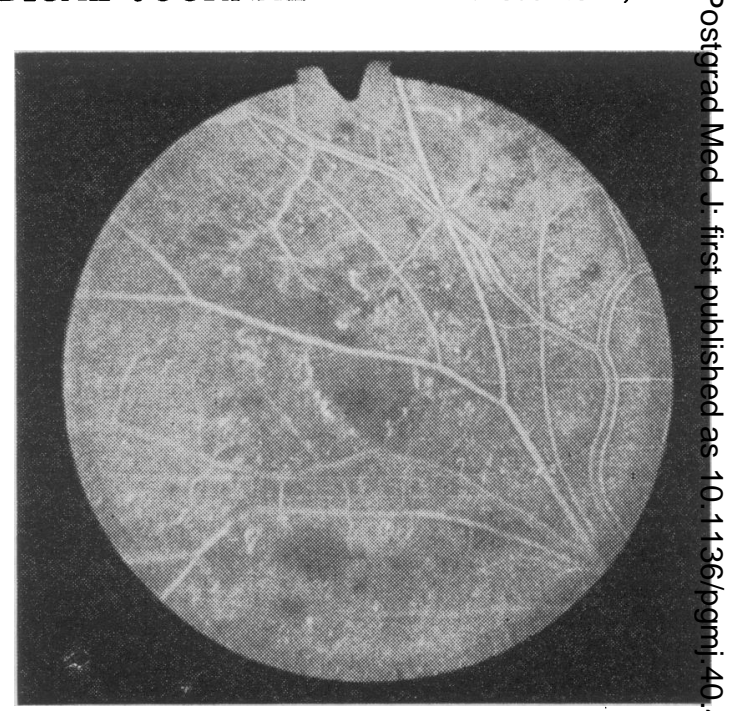

FIG. 2.-Early venous phase flourescein photograpta of the same area as Figure 1. The fluorescein appears white filling the whole of the arterioles but only the edges of the veins, because the blood from the periphery of the retina is not ye fluorescent. Numerous microaneurisms can be seen appearing as small white dots, many of them are invisible in Figure 1. The hæmorrhage appear as dark patches obscuring the back ground fluorescence.

of differing duration of disease. A prospective survey of degenerative disease in growth oaset diabetics entering the second decade of diag nosed diabetes was undertaken by Hardie Jackson, Johnston and Kelly (1956) who caf culated an index of control, taking into accourit both the strictness of control and the duration of treatment. When this index was plotter against the severity of retinopathy there was close correlation for the whole group of patients with diabetes of 10-29 years' duration. Plot: ting merely duration of disease against severity of retinopathy produced a moderate correlation for cases of less than 15 years dura. tion, an expression of the latent period required for the retinopathy to become manifest. How ever after that period the duration of disease was of little importance in determining the severity of retinopathy. Control was related to severity of retinopathy over the whole periog of the investigation, in the sense that bad corp trol was associated with severe retinopathy; this longer the duration of bad control the worse the retinopathy was likely to be. These cont clusions are supported by Collyer and Hazlett (1961) who found in a survey of 100 growt onset diabetics that all cases of severe retinof pathy were poorly controlled. 


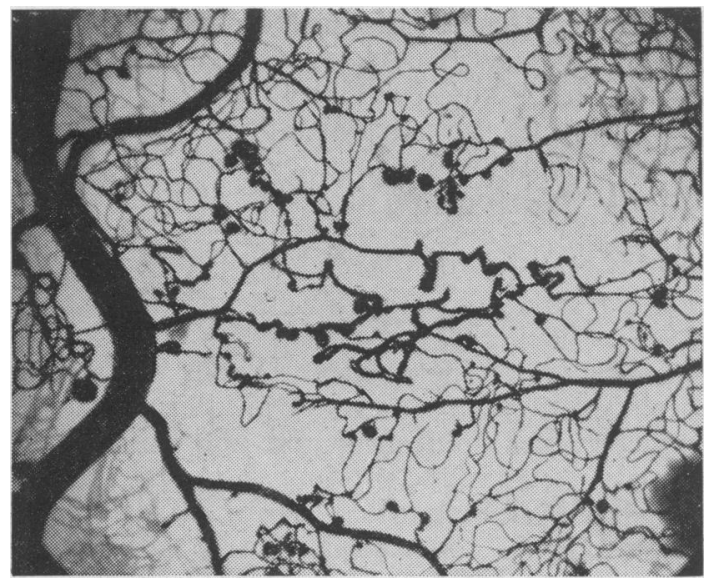

FIG. 3.-An injected specimen of retina showing an area of capillary closure in the centre of the photograph. A few dilated tortuous capillaries remain open; microaneurisms are seen on these vessels and those bordering the area of closure. Photograph supplied by Professor N. Ashton.

\section{Pathology}

Investigation of the pathology of diabetic retinopathy has been assisted by the development of new methods of histological examination. During the past 20 years a considerable amount of energy has been devoted to the problem. Ballantyne (1947) studying flat preparations of the whole retina rediscovered the microaneurisms. Ashton (1953) using injection techniques drew attention to the areas of capillary closure. More recently Kuwabara and Cogan (1960) using controlled tryptic digestion were able to isolate the blood vessels from the retinal tissue and study their histology in greater detail.

The use of injected preparations (Fig. 3) has revealed scattered areas of capillary closure related to the arterioles, but not localized to any one part of the retina; in these areas a few large dilated capillaries persist. Microaneurisms are found on these capillaries and also bordering the area of closure. Around the edge new loops of dilated capillaries form, derived from the venous capillaries. (Ashton, 1963).

Digest preparations allow study of the endothelial cells. In normal capillaries they are distributed regularly as a lining to the basement membrane, which splits to enclose the mural cells or pericytes scattered along the capillary. Ashton (1963) has studied the behaviour of the endothelial cells and finds that in areas of capillary closure the empty vessels are reduced to thin tubes of basement membrane, the endothelial cells having migrated to the nearby open capillaries. Endothelial cells proliferate in response to hypoxia, a change seen in the new capillary loops bordering areas of closure and in microaneurisms.

Microaneurisms are not specific lesions of diabetic retinopathy for they are also encountered in a number of other conditions in which retinal hypoxia occurs, for example venous thrombosis, macroglobulinæmia and Eales' disease. They appear confined to the retina, for though superficially similar lesions are seen in the kidney in intercapillary glomerulosclerosis, Volk (1956) considers them to differ from retinal microaneurisms. Controversy exists about the origin of microaneurisms; most appear to come from outpouchings on the capillary wall though some at least start from dilated capillary loops (Ashton, 1951) whose contiguous walls adhere and break down. They pass through a cycle of changes (Cogan, Toussaint and Kuwabara, 1961), endothelial proliferation, deposit of PAS staining material on the basement membrane, lipoid infiltration and disintegration.

So far attention has been focussed on the vascular changes ocourring in diabetic retinopathy, but Wolter (1961) and Bloodworth (1962) both stress the extent of neuronal degeneration, and Wolter claims to have demonstrated a proliferation and degeneration of antidromal nerves. Ashton (1963) has shown that areas of neuronal degeneration are closely related to areas of capillary closure.

The basic lesion in diabetic retinopathy would appear to be capillary olosure. Most authorities would agree that new vessel formation is a secondary process induced by prolonged tissue anoxia; but the mechanism of capillary closure is still obscure. Earlier thoughts that this might have been due to tissue swelling resulting from a primary metabolic injury (Ashton, 1959) have not been supported (Ashton, 1963). A gradual hyaline thickening of the basement membrane of arterioles throughout the body in diabetes affects the retinal vessels and may be responsible for producing a slow ischæmia with lowered capillary pressure and olosure (Ashton, 1963). Cogan and others (1961) have noted that the mural cells in the walls of the retinal capillaries are frequently degenerate in diabetic retinopathy; they postulate a specific lesion and consider that microaneurisms arise from these sites through weakening of the basement membrane. Loss of pericytes may also result in failure to control capillary tone with redistribution of the retinal 
circulation and closure of some capillaries. Increased permeability of the capillaries due to endothelial injury (Ballantyne, 1945), and embarrassment of the venous outflow are other possible factors in the development of retinopathy. Finally the question remains whether the vascular changes, by no means specific, are primary or secondary to the neuronal lesions already mentioned (Toussaint, Cogan and Kuwabara, 1962).

From a discussion of the pathogenesis of diabetic retinopathy arises the further problem of the factors in the diabetic state which determine the onset of the retinopathy. An association between adrenocortical hyperfunction and diabetic retinopathy has been suggested by Becker, Maengwyn Davies, Rosen, Friedenwald and Winter (1954) based on clinical, biochemical and pathological evidence. During pregnancy hormonal changes occur which include adrenocortical hyperactivity; the onset of diabetic retinopathy and its resolution after delivery have been observed, also the worsening of established retinopathy during the last trimester followed by improvement after pregnancy. The development of retinal microaneurisms has been noted as a result of prolonged administration of intravenous ACTH to patients without diabetes. The association of deterioration of retinopathy with poor control of the diabetes can be interpreted in terms of the increase of adrenocortical activity which accompanies infection and ketosis. There is no direct test for adrenocortical hyperfunction, but the Thorn test (depression of circulating eosinophils in response to a test dose of ACTH) is negative in hypofunction. A negative test was obtained in $50 \%$ of a group of diabetics without retinopathy, but the response could be obtained with a test dose of cortisone suggesting that adrenocortical hypofunction was responsible for the failure. In contrast all patients with retinopathy gave a positive response. Indirect evidence of adrenal hyperfunction in diabetics with retinopathy, and hypofunction in those without retinopathy, comes from a determination of the free oxysteroid excretion which is raised in cases of retinopathy and lowered in those without retinopathy. The excretion of 17-hydroxycorticosteroids is similarly altered but the changes are less marked (Maengwyn Davies, Lerman, Pogell, Stone, and Friedenwald 1956). The therapeutic response to pituitary ablation, adrenalectomy and testosterone will be discussed later; all of these measures result in a reduction of adrenocortical function.
The renal lesions of the Kimmelsteil Wilsof (KW) kidney, are found in many cases of severe retinopathy; Ashton (1958) found them present in all cases examined by autopsy. Becker an others (1954) demonstrated evidence of adreno? cortical hyperfunction in cases of $\mathrm{KW}$ kidney at autopsy. There was an increase in weigh of the adrenals by $24 \%$, lipoid vacuolisation in the zona fasciculata in $86 \%$ of cases and greater incidence of adrenal adenomass Experimental evidence from rabbits shows tha administration of anterior pituitary extract\$ and cortisone in healthy and alloxan diabetic animals results in the production of renal lesions considered similar to those of KW kidney Becker (1952) reported a rise from $30 \%$ tळ $70 \%$ in the incidence of these lesions aftep cortisone injection when the animals were alloxan diabetic. Rosen (1956) reviewing the evidence for adrenal hyperfunction in diabetic retinopathy concluded that the failure to pro: duce capillary microaneurisms consistently iros experimental animals, and their infrequency iro man after prolonged steroid therapy, constituted? a weakness in the hypothesis.

Poulsen and Larsen (1961) have investigated the changes of intraocular pressure which accompany the fluctuation of blood sugar leves Both hyperglycæmia and hypoglycæmia mays produce a fall in the ocular tension. Hypere glycæmia due to insulin lack is a more potext factor than alimentary hyperglycæmia and māy produce a $10 \%$ fall. Acute hypoglycæmia mays result in a fall of as much as $20 \%$. The variations are more marked in severe diabetics It is argued that these changes put a mechanica stress on the walls of the retinal blood vessels depriving them of their normal support. Mooney (1963) reports two clinical observations in sup port of this idea. In a patient with mild diabetic retinopathy the second eye which was blind from glaucoma was free of retinopathy. Another patient with severe retinopathy was observed tos. have low ocular tension in association with vitreous hæmorrhage, which rose to normal asं the hæmorrhage resolved.

A rise in the level of serum lipids is founds in many diabetics. It increases in patients with retinopathy and is even higher in those with nephropathy, but as it occurs in other diseasesn unaccompanied by retinopathy it must be considered a non-specific change (Larsen, 1960) $N$ The same can be said of the protein-boundw carbohydrate and hexosamine fractions whiche are increased in diabetic retinopathy. Ashtono (1959) has drawn attention to the fact that noned of these biochemical changes can be invoked? 
to explain the localisation of the lesions to the retina.

\section{Treatment}

The legion of treatments advocated at various times for this complication is a sure indication of the unsatisfactory results obtained, so much so that many consider the condition untreatable. A fundamental difficulty lies in deciding the criteria on which treatment may be assessed. Some of the manifestations of retinopathy, for example retinitis proliferans, are consequent on extensive injury to the tissues, whilst others, hæmorrhages and microaneurisms, are much closer to the primary lesion of diabetic retinopathy. Because the natural evolution of the retinopathy is slow it is important to look for improvement in those clinical manifestations which are close to the primary lesion, as the others may continue to progress under the momentum of the injury already inflicted. This applies particularly to retinitis proliferans which is a connective tissue reaction, and possibly also to exudates which are never seen in the absence of established retinopathy.

A comparison of the results of different workers is difficult because of the lack of uniformity in their criteria of assessment. Repeated estimation of the visual acuity which has the advantage of a close relationship to the amount of useful vision experienced by the patient, is unfortunately a poor guide to the progress of the retinopathy; in cases where vitreous hæmorrhage is occurring wide fluctuations are encountered in the visual acuity, irrespective of the trend of the disease. Changes in refraction, cataract, and intercurrent ocular disease can also upset the visual acuity. Joplin, Hill, Scott and Fraser (1962) have studied serial retinal photographs of selected areas of the retina, assessing them in terms of five components, hæmorrhages and microaneurisms, venous dilatation, new vessel formation, retinitis proliferans and exudates. Using a four-point scale of severity they were able to demonstrate the trend of retinopathy in treated and untreated cases. It is not possible to study the whole fundus by photography so Contreras, Field, Hall and Sweet (1962) preferred to document their cases by repeated fundus drawings made with the aid of the binocular indirect ophthalmoscope, affording a diagram of the whole fundus and vitreous but losing the accurate detail of the retinal photograph.

The natural history of diabetic retinopathy is very variable both in the rate of deterioration and the incidence of periods of inactivity, sometimes of arrest. Beetham (1963) has observed spontaneous arrest for periods of $1-9$ years in $10 \%$ of a group of patients with proliferative retinopathy who received no specific treatment for the complication. These observations cast grave doubt on the significance of treatment in isolated cases of improvement, and indicate the need for some form of control in any therapeutic trial relating to diabetic retinopathy.

Three lines of treatment will be discussed, pituitary ablation, anabolic steroids, and low fat diets; in addition light coagulation will be mentioned. Other methods of treatment have included the exhibition of vitamin $B_{12}$, rutin, lipotropic substances, and œstrogens but with little success. The impetus for pituitary ablation came from the observation by Poulsen (1953) of remission and eventual clearing of retinopathy in a woman who suffered from postpartum necrosis of the pituitary, with clinical Simmonds disease and increased sensitivity to insulin. Ablation can be produced by hypophysectomy (Luft, Olivecrona, Ikkos, Kornerup, and Ljunggren, 1955; Kinsell, 1957; Schimek, 1956; Javid, Gordon and Erickson, 1958; Vannas, Hernberg and Björkesten, 1959) performed transcranially or trans-sphenoidally; alternatively the pituitary stalk may be divided and a diaphragm inserted to prevent healing of the portal venous system (Contreras and others, 1962). Irradiation with a neutron beam (Sangalli, 1961), and implantation of radioactive Yttrium-90 seeds through a cannula passed across the top of the nasal cavity under radiographic control (Fraser and Joplin, 1961) are alternative methods. Intracranial surgery in diabetic patients is fraught with more risk than usual from thrombosis and infarction of the retracted lobes of the brain; for that reason the nasal approach is sometimes preferred. Surgical hypophysectomies produce complete ablation of immediate onset in the majority of patients. After an Yttrium implant the first sign of decreased activity is a sharp drop in the insulin requirement, usually manifest on the fifth day (Joplin and others, 1962). Irradiation from the cyclotron takes longer to act and is not free from risk of damage to surrounding structures. Stalk section like Yttrium implant produces a proportion of incomplete ablations, but present evidence though not conclusive suggests that there may be little difference in the effect on retinopathy of partial or complete ablation. Improvement in nearly all aspects of retinopathy was reported by Contreras and others (1962), but Joplin and others (1962) 
found only dilated veins, hæmorrhages and new vessels favourably influenced. This series of patients has been followed and additional patients recruited; in 1963 Hill reported that about one-third of them showed improvement in respect of dilated veins, hæmorrhages and new vessels, none was worse; but retinitis proliferans deteriorated in half the cases and exudates showed little change. By contrast a comparable unimplanted group showed no significant change in respect of venous dilatation, hæmorrhages and new vessels. At a recent symposium held to consider the effects of hypophysectomy and adrenalectomy on diabetic retinopathy (Luft, 1962) most speakers reported arrest or improvement in about half their cases. Operative mortality was not serious but there was a considerable mortality in the years of follow-up due in many cases to renal failure. Gordon and Javid (1962) reviewed the metabolic effects of hypophysectomy and considered that patients could be maintained in the Houssay state for at least five years. Limited renal function was the major hazard.

Anabolic steroids have been given to counteract the changes in serum proteins occurring in diabetic retinopathy, a fall in serum albumin and a rise in the alpha-2 globulins which contain lipoproteins and mucopolysaccharides (Dardenne, 1961). These changes are considered to be due to the action of glucocorticoids, consequent on pituitary and adrenal hyperfunction. Dardenne has treated 48 patients for periods of eighteen months and longer with Decadurabolin and Orgabolin, following the effect with retinal photographs; 8 patients improved, 34 were stationary and 6 deteriorated. Saskin, Waldman and Pelner (1951) treated 28 patients with testosterone propionate, and found that 11 showed no fresh hæmorrhages, 10 were improved and 7 unchanged after periods of two to six months. Valk (1960) reported a single case of improvement. The duration of these trials was too short to form an opinion about the effectiveness of treatment, and in the series of cases presented by Dardenne no mention is made of the criteria by which the results were judged.

The extent to which hard exudates are due to intracellular fat liberated by necrosis, or serum lipid infiltration, is uncertain (Van Eck, 1959), but of 10 patients on a low fat diet (20 grams a day) for an average period of one year exudates were reduced in 5 cases and slightly reduced in a further 3; vascular changes and hæmorrhages were uninfluenced. King, Dobree, Kok, Foulds and Dangerfield (1963) treated their patients on a low fat diet to whith unsaturated vegetable fats were added; the was a reduction of the total serum lipids and an improvement in exudates in 21 out of 86 cases. In a comparable group of untreated cases 11 improved, 4 were unchanged and were worse. Unfortunately the disappearange of exudates left a permanent scotoma so thgit there was no significant improvement in visio

Light coagulation of areas of active retinspathy (producing a controlled local coagulation necrosis by means of a high intensity light source, an effect similar to the natural phen $\vec{\theta}-$ menon of an eclipse burn) has been advocated by Wetzig and Worlton (1963), and the preg liminary results show moderate success.

The results of treatment are unsatisfacto though superior to comparable untreated groups; the management of patients must be assessed in this context. Pituitary ablation produces considerable general effects and roquires careful replacement therapy wi adequate medical supervision always available. It is likely to be superseded when the cause of retinopathy is better understood, but for present should be considered when the retingpathy is severe and active but not too advanceg, provided there is no renal impairment.

OTHER OCULAR MANIFESTATIONS

An extensive survey of the ocular corr plications of diabetes was made by Waite and Beetham (1935) who examined 2,002 diabetic patients on the occasion of their first admission to hospital. The series included many nea cases and some already under treatment for period. To obtain an estimate of the incidenge of these ocular conditions in patients not suffering from diabetes they examined concurrent $\mathrm{B}$ another series of 457 patients also admitted hospital for the first time. Mild chronic i fections of the external eye were more common in the diabetic group and included squamow blepharitis and conjunctivitis from which staphylococci were often cultured; surprising民 meibomian cysts and styes were not commo Xanthelasma occurred more frequently diabetics, but xanthoma diabetica was no encountered. Weakness of accommodation was found in $21 \%$ of patients under 50 years of age; it was never severe and was associated in $40 \%$ of the cases with a history of transieiti refractive changes suggesting that it was lere ticular in origin. Evidence of depigmentation of the iris was found in $6 \%$ of the diabetic 
patients as compared to $2 \%$ of the other group. Poor dilatation of the pupils following the instillation of mydriatics for routine examination was found in $4 \%$ of the diabetic cases, the patients having normal pupillary reactions. Argyll-Robertson pupils occurred in $2.8 \%$ of the diabetes, in half of the cases there was no clear indication of syphilitic origin. Iridocyclitis occurred with equal frequency in both groups, $1.3 \%$ of cases. Senile cataract was found to have a similar incidence in the two series of patients in all age groups. Amongst juvenile diabetics cataract was found in $4 \%$ of cases of which half were poorly controlled, it progressed at varying rates and once established was uninfluenced by diabetic control. Transient refractive changes were reported in $6 \%$ of patients. 7 male diabetic patients were found to have changes typical of tobacco amblyopia, but in no case was an affection of the optic nerve found specific to diabetes. Ocular muscle palsies occurred in $0.8 \%$ of the diabetic patients.

Leopold (1945) reviewed a series of 100 patients who had had 10 years careful diabetic management and compared his findings with those of Waite and Beetham (1935); he found little significant change save that the incidence of retinopathy had increased.

\section{Changes in the Lens and Refraction}

Because of the widely fluctuating blood sugar levels, and alteration in the state of hydration of the tissues, changes in the refraction of the eye are frequent in uncontrolled diabetes. A change towards myopia is usual in uncontrolled patients with a rapid swing towards hypermetropia when the blood sugar is brought under control. There is a diversity of opinion about the mechanism of these changes (Lawrence, Oakley and Barne, 1942; Duke Elder, 1949) though they appear to be osmotic effects acting on the crystalline lens. A change of 2-3 dioptres is usual but it may be exceeded; it is often astigmatic affecting one meridian more than another. With the onset of hypermetropia the patient may be considerably inconvenienced particularly when attempting to read, but it is seldom necessary to prescribe glasses as the changes are transient lasting only a week or two when the diabetes is adequately controlled.

Transient changes are seen in the crystalline lens of the eye in diabetic coma (Lawrence and others, 1942), due to the intense dehydration which also produces profound ocular hypotension, they disappear rapidly when the condition is brought under control. In these cases the globe of the eye feels very soft to the fingers and with the ophthalmoscope opacities can be seen in the crystalline lens which take the form of wavy lines due to capsular folding, with vacuoles and clefts, and occasionally denser opacities. Transient lens changes have also been noted following the control of severe diabetes; they take differing forms. Lawrence (1946) reported two cases in which radial cortical opacities appeared and lasted 2-4 weeks. Diabetic cataract is a rare entity occurring bilaterally in young patients. Snowflake opacities appear in the anterior and posterior cortex under the lens capsule and progress to complete opacity sometimes within a few weeks; its incidence and relation to diabetic control have been noted. Senile cataract though no more common in the diabetic probably matures faster (Scott, 1953) so that the total incidence may be higher. In any event a routine urine test is essential in all cases of cataract, both for the detection of undiagnosed diabetes and to ensure that the disease is adequately controlled before operation. Both types of cataract can be removed surgically with reasonable prospects of useful vision provided the eye is otherwise healthy, especially free from new vessels on the iris and serious retinopathy. Post-operative hæmorrhage and iridocyclitis are more liable to occur in the diabetic patient and form the major hazards to successful cataract extraction (Nutt, 1953).

\section{Changes in the Iris}

Oedema and vesiculation of the pigment epithelium on the posterior surface of the iris results from infiltration of the cells with glycogen and their consequent degeneration. Ultimately the pigment is liberated and deposited on the structures bounding the anterior chamber of the eye, the posterior surface of the cornea and the anterior capsule of the lens. These deposits and the depigmentation of the iris can be detected with the slit lamp microscope. The gross thickening of the pigment epithelium is probably the basis of the poor dilatation of the pupil in response to mydriatic drugs which has already been mentioned.

The growth of new vessels on the surface of the iris is often associated with severe proliferative retinopathy; they are first seen on the anterior surface just beyond the pupillary margin, appearing as a dull red patch which spreads round the pupil and peripherally. New vessels also develop in the angle of the 
anterior chamber at the same time; they are only visible by gonioscopy using a special contact lens, and block the filtration angle leading to hæmorrhagic glaucoma. The term rubeosis iridis is given to this neovascularisation.

Diabetes does not influence the incidence of iridocyclitis (Waite and Beetham, 1935), and in a recent review of the concept of diabetic iritis Woods (1961) came to the conclusion that there was no form of iridocyclitis specific to diabetes, nor could the disease be considered an ætiological factor in uveitis.

\section{Optic Neuritis}

Skillern and Lockhart (1959) report 14 cases of optic neuritis in patients with uncontrolled diabetes. The onset was gradual and the condition bilateral in most cases, papillitis was observed in some cases and optic atrophy in others; a central scotoma or peripheral contraction of the field of vision was found. Control of the diabetes prevented further deterioration but only 3 patients experienced any improvement of vision. The condition was considered to be due to the toxic effects of diabetes on the optic nerve in susceptible subjects; the low incidence of neuropathy, present in only 3 of the cases, and the short duration of the diabetes were thought to differentiate it from neuropathic and vascular disturbances. Duke Elder (1940b) described the condition as of sudden onset, often bilateral, more common in males and showing a dense sharp-edged scotoma which was central, pericentral or cæcocentral (that is, a loss of visual field centred on or around the fixation point, or lying between it and the blind spot); the prognosis was uncertain, rapid resolution or persistence with consequent optic atrophy might occur. Scott (1953) drew attention to the acknowledged sensitivity of diabetic patients to the toxic effects of tobacco as manifest by tobacco amblyopia, and agreed with other authors (Waite and Beetham, 1935; Walsh, 1947) in doubting the existence of a specific diabetic optic neuritis. In assessing the evidence it should be remembered that there are numerous causes of optic neuritis and some cases remain unassigned despite full investigation. The possibility of a genetic factor in some of these cases is suggested by the report of primary optic atrophy in two patients, mile and female siblings with longstanding diabees unsatisfactorily controlled (Tunbridge 夏d Paley, 1956).

\section{Ocular Palsies}

돌

Diabetic ophthalmoplegia affects the third?or sixth cranial nerves, rarely the fourth (Kifig, 1959), and often occurs against a backgroumd of previous cranial monoplegia which bas recovered spontaneously without further coinplication. It is a complication of middle aged patients with controlled diabetes or mild unrecognised disease; peripheral neuropathy atd retinopathy are not necessarily associated. Goldstein and Cogan (1960) reviewed 22 cases of third nerve palsy considered after investigation to be due to diabetes, and compad them with 39 other cases due to various causes. The onset of diabetic ophthalmoplegia sudden, often preceded or accompanied byoa homolateral headache, closely resembling the clinical presentation of an intracranial aneurism. Paralysis of the external muscles was partial or complete but the pupil was usually spaned and internal ophthalmoplegia occurred in ofly 5 cases, being incomplete in 2. By courast 29 out of the 39 other cases which incladed several due to aneurism, were affecteo to ty internal ophthalmoplegia. All the diafectic cases recovered, the time varied from six tays to four months, but repeated attacks we found in several patients.

\section{Other Complications}

It remains to mention briefly two other complications of diabetes: subjective viswal symptoms in hypoglycæmia, which take variens forms, for example blurring of near visiên, diplopia or luminous scotomata, which âre usually constant for each patient; and $\overline{\mathrm{T}}$ e rare condition of lipæmia retinalis seen whien the fat content of the blood is grossly raised in severe untreated diabetes, so that the retimal vessels present a peculiar milky pallor turnmig to pink near the optic disc.

I wish to thank Professor N. Ashton of Institute of Ophthalmology for his kindness in suppyying the photograph of the injected preparation of retina (Fig. 3), and Mrs. M. Engel of the Hammsmith Hospital who prepared the retinal photographs.

\section{REFERENCES}

Ashton, N. (1951 : Diabetic Retinopathy, Proc. roy. Soc. Med., 44, 747.

Ashton, N. (1958): Diabetic Micro-Angiopathy, Bibl. ophthal. (Basel), 52, 1.

Astron, N. (1959): Diabetic Retinopathy, Lancet, ii, 625.

Ashron, N. (1962): Diabetic Retinopathy in Disorders of Carbohydrate Metabolism, p. 195, ed. D. A. Pyke, London: Pitman Medical. 
Ashton, N. (1963): Studies of the Retinal Capillaries in Relation to Diabetic and other Retinopathies, Brit. J. Ophthal., 47, 521.

Ballantyne, A. J. (1945): Retinal Changes associated with Diabetes and with Hypertension, Arch. Ophthal. (Chicago), 33, 97 -quoted by Ashton (1963).

Ballantyne, A. J. (1947): The State of the Retina in Diabetes Mellitus, Trans. ophthal. Soc. U.K., 66, 503.

BECKER, B. (1952): Diabetic Retinopathy, Ann. Intern. Med., 37, 273.

Becker, B., Maengwyn Davies, G. D., Rosen, D., Friedenwald, J. S., and Winter, F. C. (1954): The Adrenal Cortex and B-Vitamins in Diabetic Retinopathy, Diabetes, 3, 175.

Beetram, W. P. (1963): Visual Prognosis of Proliferating Diabetic Retinopathy, Brit. J. Ophthal., 47, 611.

BLOODWORTH, J. M. B. (1962): Diabetic Retinopathy, Diabetes, 11, 1.

Cogan, D. G., Toussaint, D., and Kuwabara, T. (1961): Retinal Vascular Patterns: Diabetic Retinopathy, A.M.A. Arch. Ophthal., 66, 366.

Collyer, R. T., and HAzLETT, B. E. (1961): Retinopathy and Neuropathy in one hundred Growth-onset Diabetic Patients, Canad. med. Ass. J., 85, 1328.

Contreras, J. S., Field, R. A., Hall, W. A., and Sweet, W. H. (1962): Ophthalmological Observations in Hypophyseal Stalk Section: Report of 8 Cases of Advancing Diabetic Retinopathy, A.M.A. Arch. Ophthal., 67, 428 .

DARDENNE, U. (1961): The Therapeutic Applications of Anabolic Steroids in Ophthalmology, Acta Endocr. $(K b h),$.39 , Suppl. 63, p. 143.

DOllery, C. T., HoDGE, J. V., and ENGel, M. (1962): Studies of the Retinal Circulation with Fluorescein, Brit. med. J., ii, 1210.

Duke EldER, W. S. (1940a): Diabetic Retinopathy: Textbook of Ophthalmology, Vol. III, p. 2729, London: Kimpton.

DUKE ELDER, W. S. (1940b): Endogenous Toxins, ibid, p, 3005.

DUKe EldER, W. S. (1949): Changes of Refraction in Diabetes Mellitus: Textbook of Ophthalmology, Vol. IV, p. 4364, London: Kimpton.

FraSeR, R., and Joplin, G. F. (1961): Modern Trends in Endocrinology, ed. H. Gardiner Hill, London: Butterworth-quoted by Joplin and others (1962).

Goldstein, J. E., and Cogan, D. G. (1960): Diabetic Ophthalmoplegia with special Reference to the Pupil, A.M.A. Arch. Ophthal., 64, 592.

GoRDON, E. S., and JAVID, M. (1962): Metabolic Studies in Hypophysectomy for Diabetic Vascular Disease, Diabetes, 11, 470.

Hardin, R. C., JAcKson, R. L., Johnston, T. L., and Kelly, H. G. (1956): The Development of Diabetic Retinopathy. Effects of Duration and Control of Diabetes: Diabetes, 5, 397.

HILL, D. W. (1963): Unpublished communication.

JAvip, M., Gordon, E. S., and ERICKSON, T. C. (1958): Hypophysectomy in Severe Diabetes: 1, Neurosurgical Aspects, J. Neurosurg., 15, 504.

Jensen, V. A., and LundBaeK, K. (1955): Diabetic Pigmentopathy of the Macula Lutea: A new Ophthalmological Anomaly in long-term Diabetes, Ophthal. (Basel), 129. 89-quoted by Larsen (1960b).

Joplin, G. F., Hill, D. W., Scotr, D. J., and Fraser, T. C. R. (1962): Pituitary Ablation in the Treatment of Diabetic Retinopathy in Disorders of Carbohydrate Metabolism, p. 207, ed. D. A. Pyke, London: Pitman Medical.

KeIDING, N. R., Root, H. F., and MARBLE, A. (1952): Importance of Control of Diabetes in Prevention of Vascular Complications, J. Amer. med. Ass., 150, 964-quoted by Larsen (1960a).

KING, F. P. (1959): Paralyses of the Extraocular Muscles in Diabetes, A.M.A. Arch. intern. Med., 104, 318.

KING, R. C., DobreE, J. H., D'A KoK, FouldS, W. S., and DANGerfielD, W. G. (1963): Exudative Diabetic Retinopathy, Brit. J. Ophthal., 47, 666.

KINSELL, L. W. (1957): Hypophysectomy in Unstable Diabetics with Progressive Retinal and Renal Vascular Disease, Bull. N.Y. Acad. Med., 33, 171.

Kuwabara, T., and Cogan, D. G. (1960): Studies of Retinal Vascular Patterns: Part I Normal Architecture, A.M.A. Arch. Ophthal., 64, 904.

LARSEN, H. W. (1960a): Incidence of Diabetic Retinopathy, Acta ophthal. (Kbh.), 38, Suppl. 60, p. 17.

LARSEN, H. W. (1960b): Development and Course of Diabetic Retinopathy, ibid, p. 21.

LAWRENCE, R. D., OAKLeY, W., and BARNE, I. C. (1942): Temporary Lens Changes in Diabetic Coma, Lancet, ii, 63 .

LAWRENCE, R. D. (1946): Temporary Cataracts in Diabetes, Brit. J. Ophthal., 30, 78.

LEOPOLD, I. H. (1945): Diabetes Mellitus as Observed in 100 Cases for 10 or more Years: III Ocular findings, Amer. J. med. Sci., 209, 16.

LEOPOLD, I. H., ed. (1961): Survey, Ophthal., 6, 498.

LufT, R., OliVeCRONA, H., IKKOS, D., KORNERUP, T., and LJUNGgren, H. (1955): Hypophysectomy in Man: Further Experiences in Severe Diabetes Mellitus, Brit. med. J., ii, 752.

LuFT, R. (1962): The Use of Hypophysectomy in Juvenile Diabetes Mellitus with Vascular Complications, Symposium on the Influence of Hypophysectomy and of Adrenalectomy on Diabetic Retinopathy, Diabetes,
11, 461.

Maengwyn Davies, G. D., Lerman, S., Pogell, B. M., Stone, H. H., and Friedenwald, J. S. (1956): The Adrenal Cortex in Diabetic Retinopathy: Urinary 17-hydroxycorticosteroid Excretion Studies, Bull. Johns Hopk. Hosp., 99, 16.

MOONEY, A. J. (1963): Diabetic Retinopathy-A Challenge, Brit. J. Ophthal., 47, 513.

NuTT, A. B. (1953): Lens Extraction in Diabetic Patients, ibid, 37, 725. Poulsen, J. E. (1953): Recovery from Retinopathy in a Case of Diabetes with Simmonds' Disease, Diabetes,
2, 
Poulsen, J. E., and LARSEN, H. W. (1961): Variations of the Intraocular Tension as a Pathogenetic Factior in Diabetic Retinopathy. Proc. 4th Congress de la Fédération international du Diabète, p. 536, Ed.

M. Demole, Genève: Editions Médicine et Hygiene.

Rosen, D. A. (1956): Trans. Canad. ophthal. Soc., 8, 122.

SANGALLI (1961): see Leopold (1961).

Saskin, E., Waldman, S., and Pelner, L. (1951): Diabetic Retinopathy: A New Approach to Therapy with a Steroid Hormone-Testosterone Propionate, Amer. J. Ophthal., 34, 613.

SCHIMEK, R. A. (1956): Hypophysectomy for Diabetic Retinopathy, A.M.A. Arch. Ophthal., 56, 416.

SCOTT, D. J., DollerY, C. T., Hill, D. W., HoDGe, J. V., and FRASER, T. C. R. (1964): Fluorescein Studges of Diabetic Retinopathy, Brit. med. J., i, 811.

ScoTT, G. I. (1951): Diabetic Retinopathy, Proc. roy. Soc. Med., 44, 743.

ScoTT, G. I. (1953): Ocular Complications of Diabetes Mellitus, Brit. J. Ophthal., 37, 705.

SkIllern, P. G., and LOCKHART, G. (1959): Optic Neuritis and Uncontrolled Diabetes Mellitus in 14 Patientss, Ann. intern. Med., 51, 468.

Toussaint, D., Cogan, D. G., and Kuwabara, T. (1962): Extravascular Lesions of Diabetic Retinopattit, A.M.A. Arch. Ophthal., 67, 42.

TunBRIDGe, R. E., and Paley, R. G. (1956): Primary Optic Atrophy in Diabetes Mellitus, Diabetes, 5, 295. $\overrightarrow{.}$

VANNAS, S., HERNBERG, C. A., and BJORKESTEN, G. (1959): Hypophysectomy as a Therapeutic Method Proliferative Diabetic Retinopathy, A.M.A. Arch. Ophthal., 62, 370.

VALK, L. E. M. (1960): Favourable Tffect of Durabolin (19-nor-androstenolon-phenyl-propionate) on Diab悉ic Retinopathy, Ophthal. (Basel), 139, 480.

VAN ECK, W. F. (1959): The Effect of a Low Fat Diet on the Serum Lipids in Diabetes and its Significarife in Diabetic Retinopathy, Amer. J. Med., 27, 196.

Volk, D. (1956): Dissimilarity of Retinal Microaneurysm and Glomerular Nodule in Diabetes, A.M.A. Ar $\mathrm{BA}$. Ophthal., 56, 188.

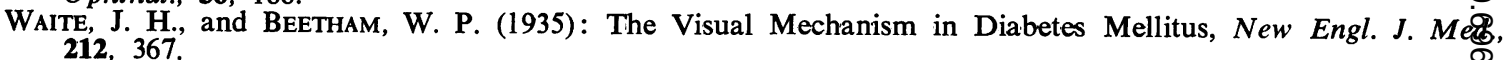
WALSH, F. B. (1947): Clinical Neuro-ophthalmology, 1st. ed., Baltimore: Williams \& Wilkins-quoted by Scgtt
(1953).

WetzIG, P. C., and Worlton, J. T. (1963): Treatment of Diabetic Retinopathy by Light-coagulation, Brit. $\overrightarrow{\mathrm{d}}$ Ophthal., 47, 539.

Wolter, J. R. (1961): Diabetic Retinopathy, Amer. J. Ophthal., 51, 1123.

Woods, A. C. (1961): Endogenous Inflammations of the Uveal Tract, p. 304, Baltimore: Williams \& Wilki 